\title{
A Dialogue Between Human Beings and Gods Integrating Religion \& Folk Customs \& Art-—A Brief Analysis of Gan Nuo Folk Customs and Dialect Vulgarisms
}

\author{
Xiao Jiugen ${ }^{1}$, Xiong Lingjun ${ }^{2}$ \\ ${ }^{1}$ Research Center of Language and Language Life, Jiangxi Normal University, Nanchang, China \\ ${ }^{2}$ Jiangxi Modern Polytechnic College, Nanchang, China
}

\section{Email address:}

jxsdxjg666666@sina.com (Xiao Jiugen), 15568659@qq.com (Xiong Lingjun)

\section{To cite this article:}

Xiao Jiugen, Xiong Lingjun. A Dialogue Between Human Beings and Gods Integrating Religion \& Folk Customs \& Art_—A Brief Analysis of Gan Nuo Folk Customs and Dialect Vulgarisms. Science Innovation. Vol. 8, No. 4, 2020, pp. 91-96. doi: 10.11648/j.si.20200804.12

Received: April 8, 2020; Accepted: June 20, 2020; Published: June 29, 2020

\begin{abstract}
Gan Nuo folk culture has a long history, rich content and far-reaching influence. According to archaeological findings, this folk culture originates from the Shang and Zhou Dynasties or even earlier ancient times. It is a form of primitive folk customs integrating religion, folk customs and art as a mode of dialogue between human beings and gods. With the rapid development of social history, the innovation of people's concepts, the contents of Gan Nuo also has changed a lot, adding new elements of modern culture and developing towards the direction of popular, life-oriented and entertaining, and even to service in Gan Po the development of economy, trade and industry, to show its unique artistic charm. It is no exaggeration to say that the folk culture of Gan Nuo is not only an important part of the culture in Gan Po, but also the "living fossil" of China's primitive opera and dance. In the process of its development, a large number of dialects and vulgarisms reflecting Nuo customs have also sprang up with rich and colorful contents. These dialects and vulgarity have very distinct regional characteristics, either to present the sacrificial ceremony, or to present the nuo drama art, or to present the folk customs. Currently, we should not only tap and use this national intangible cultural heritage such as Gan Nuo efficiently, but also protect and develop them to inject new vitality into them in the course of promoting ethical progress in the new era.
\end{abstract}

Keywords: Gan Nuo Folk Culture, Dialogue Between Human Beings and Gods, Living Fossils, Dialects and Vulgarisms, National Intangible Cultural Heritage

\section{融宗教·民俗·艺术于一体的人神对话 赣倠民俗事象及方言俗语刍议}

肖九根 ${ }^{1}$, 熊玲君 ${ }^{2}$

1江西师范大学语言与语言生活中心, 南昌, 中国

2江西现代职业技术学院, 南昌, 中国

\section{邮箱}

jxsdxjg666666@sina.com（肖九根），15568659@qq.com（熊玲君）

摘要：赣傩民俗文化历史悠久, 内容丰富, 影响十分深远。据考古发现, 这一民俗文化滥解于商周乃至更早的上古时 期，是一种融宗教、民俗、艺术于一体的原始民间艺术，也是一种人神对话方式。随着社会历史的快速发展，人们思 想观念的不断革新, 赣傩所表现的内容也发生了很大变化, 其中渗透着许多现代文化新元素, 日益朝着大众化、生活 化、娱乐化方向发展，甚至还以之服务于赣鄱经济产业的发展，向世人展示其独特的艺术鬼力。可以毫不夸张地说， 
赣傩民俗文化不单是赣鄱文化的一个重要组成部分，还是中国原始戏舞的“活化石”。在赣傩文化发展的过程中，大量 反映倠俗事象的方言俗语也随之产生, 这些方言俗语或表现祭祀仪式, 或表现倠戏艺术, 或表现民俗风情, 具有十分 鲜明的地域特色。今天, 进行新时代精神文明建设, 对于赣倠这类国家级非物质文化遗产宝贵资源, 不仅要开发利用 好, 还应保护发展好, 使之焕发出新的生机与活力。

关键词：赣倠民俗文化，人神对话，活化石，方言俗语，国家级非物质文化遗产

\section{1. 引言}

在中华民族文化的瑰宝中,除赣鄱陶瓷是一颗璀嗓光 芒的明珠之外，[1]还有赣傩也被誉为中国原始戏舞的“活 化石”。在赣鄱地区的历史上，曾有三苗、百越及吴楚等 民族的长期活动。这些民族尚鬼、崇巫、喜卜、好祀之风, 给赣鄱习俗带来了极大的影响, 也是赣傩孕育生成的本 源。赣傩渊源于上古的巫风，是一种集宗教、民俗、艺术 于一体的原始民间文化艺术，也是人神异域对话的一种方 式。据研究, 赣鄱傩祭活动距今已有两千多年的历史, 且 其原生态保存良好, 类型丰富。[2]在其发展过程中, 虽历 尽沧桑, 但依旧盛兴不衰, 成为赣鄱民俗文化中不可或缺 的组成部分。

赣傩遍及全省各地, 而其中犹以鄱阳、余干、九江、 临川、吉安、新干、宜春、南丰、乐安、敂源、万载、萍 乡、德安等地最为流行, 至今还延续着千百年来所保持的 傩舞习俗。例如, 在萍乡, 家族建有傩庙、傩队, 每逢春 节就要出演傩舞; 在乐安流坑, 素有“八房八傩班”之说, 大年新春演傩戏都要举行隆重的出傩和收傩仪式; 在南丰 石邮, 乡人大年初一至十五, 要进行祈神赐福消灾的傩事 活动。当然, 傩舞演出这一习俗并非大年新春才有, 它是 随着时节的变化而变化的, 如除迎春傩、新年初一傩、元 宵傩之外, 还有夏季的端午傩, 秋季的鬼节傩、中秋傩、 重阳傩, 冬季的腊八傩、送灶傩、除夕傩等。此外, 纪念 大事还有吉庆傩（如结婚、求嗣、生子、庆寿等活动）以 及丧葬傩。

赣傩表演的民俗文化内容丰富多样, 其表现或迎神驱 鬼, 或神话传说, 或民间故事等, 也产生了不少傩俗文化 方面的方言俗语。因而, 本文在探讨赣傩悠久历史及其民 俗文化的同时, 还就学界关注鲜少而又特殊的方言俗语作 些分析。

\section{2. “傩”所蕴含的语言学意义}

古人认为, 人鬼一体, 鬼神同源。东汉·许慎《说文・ 鬼部》释之: “鬼, 人所归为鬼。从人, 象鬼头。”又因世 人常以祖先魂灵视为神灵, 故将鬼神等同视之。也就是说, 鬼即神, 神亦灵, 灵为魂, 魂也就是鬼。所以, 《说文・ 鬼部》又云: “鬼, 神也, 从鬼, 申声。”如《论语》: “季 路问鬼神, 子曰: 未能事人, 焉能事鬼? ”在甲骨文里, “鬼” 为人戴面具状“办”, 取象于人, 也即巫术中巫师头戴面 具事神弄鬼, 且呈厉鬼怪异可怖之态, 以驱鬼疫。实质上, 这就是早期傩事活动的一种反映。
据史料记载, 这种迎神灵逐鬼疫活动先秦时期就已大 量存在, 而且绵延几千年, 乃至今天仍未断绝。关于傩事 驱疫之类的祭祀活动, 古文献多有记载, 如《周礼.占梦》: “季冬, 聘王梦, 献吉梦于王, 王拜而受之.....遂令始傩, 驱疫。”《论语・乡党》: “乡人傩, 朝服而立于阼阶。”《吕 氏春秋・季冬》: “命有司大傩, 旁磔, 出土牛, 以送寒气。” 高诱注之: “大傩, 逐尽阴气为阳导也, 今人腊岁前一日 击鼓驱疫, 谓之逐除是也。”又如《后汉书·礼仪志》: “先 腊一曰大傩, 谓之逐疫......以逐恶鬼于禁中。”

至于“傩”的读音, 古韵诺何切, 平声, 泥母歌部; 今 音nuó。关于“傩”所蕴含的意义内容, 古今学者对之作过 阐释。《说文解字・人部》云: “行有节也。从人, 难声。” 毛传: “傩, 行有节度。”意即认真谨慎, 所以从难。《诗 经・竹竿》：“巧笑之瑳, 佩玉之傩。”诚然, “傩”从“难” 声, 惟声谐矣, 故“难”亦读nuó音, 《集韵》释之“却凶恶 也。通作“傩”, 并注之“囊何切”, 歌部。“傩”，人们其后 将之用于一种富有节奏的驱鬼除疫之舞蹈。东汉·高诱《吕 氏春秋・季春》注: “命国人傩, 索宫中区隅幽暗之处, 击 破大呼, 驱逐不祥, 如今之正岁逐除是也。”魏·何晏《论 语》亦注: “傩, 驱逐疫鬼。”而清·朱骏声《说文通训定声》 则释为: “见鬼惊词......读若“傩”。此驱逐疫鬼正字, 击鼓 大呼似见鬼而逐之, 故曰“䰡”。唯经传皆以傩为之。”意即 “傩”是一个通假字, 其本字“魁”因经传皆用“傩”而为人所 忘。还有学者这样认为, 古之赣鄱人呼鸟图腾为“傩”, 这 是疫鬼辟易三舍力量之所在, 其遗风今犹延续; 民间百姓 “今仍以“倠”音或一音之转作呼声词, 如呼鸭之声为 'nuó......', 呼猪之声为 'nòu', 呼狗之声为“狗Luò、Luò', 第一声均长音, 后为短促音。”[3]的确, 赣鄱地区今有不 少地方如赣中许多乡村，呼猪为“nuò、nuò......”声，是否 与此有关? 当然, 还有待进一步考证。

由上可知, 赣傩不仅形态原始, 存类也丰富完整, 融 合了民俗、礼仪、节庆、图腾、鬼神等传统文化形态, 反 映了赣鄱先民其时的精神需求。[4]诚然, 赣鄱先民的傩祭 活动还是以祖先神灵驱除鬼疫为主, 其目的在于祈求幸 福, 禳除疫灾, 永保平安。

\section{3. 赣傩的悠久历史及其民俗文化}

赣傩是中华民族文化的一个重要组成部分, 历史十分 悠久。考古材料业已证明, 商周时期赣鄱地区就存有大量 的巫傩活动。

二十世纪末，考古文物发现：一是赣省存有不少商周 时期的傩舞面具。如新干大洋洲发现的大型商代大墓, 其 中出土的双面獠牙青铜头像、兽面神人玉饰和侧身羽人玉 
饰, 堪称赣傩面具家族的鼻祖。二是赣省存有不少商周时 期的祭祀遗迹。如大洋洲商墓就发现了与祭祀有关的诸多 现象, 傩祭主持者正是戴着刻有图案的傩舞面具驱鬼的; [5]还有樟树吴城商周遗址出土的祭坛遗迹, 是一个规模宏 大、庄严肃穆的宗教祭祀场所; [6]另外在德安猪山垅和黄 牛岭发现了两处商周时期的祭祀台遗迹, 考古学家认为那 是其时聚落居民的祭祀中心。[7]三是赣省存有不少商周时 期的傩舞乐器。傩音乐文化是赣省特有的,也是中国历史 上一份特有的文化遗产。[8]在赣省各地出土的青铜器中, 有不少为其时乐舞的演奏乐器, 诸如镈、甬钟、錞于、钮 钟、铎、铃、吹奏陶等, [9]其中有些就是用于演奏傩舞的。 这充分说明, 长江流域很早就存有对中国具有重要影响的 先进音乐文化, 正如有的学者所指出的: “长江流域的早 期青铜乐器对中国音乐文化以及中国古典音乐体系的诞 生具有相当的重要性。”[10]当然, 其后 (如春秋战国时期) 有关涉及傩舞的演奏乐器难以详述, 不仅数量多, 而且形 式也多样化, 除土著外还有巴楚式的, 也有吴越式的。如 修水上杉的环钮錞于、南昌的虎钮錞于、南昌和九江的钟 腔角钟等均属巴楚式; 樟树临江的“工渔王”钟、樟树和高 安的“能原鎛”等又属吴越式; [9]赣省古筝的出现也比中原 地区要早数百年, 如上世纪70年代贵溪崖墓中出土的春秋 古筝，就早于中原“秦筝”二百多年。凡此种种，均为赣域 巫傩文化起源于商周时期提供了有力的证据。不过, 有的 学者甚至认为赣鄱傩舞产生于商周之前,其源头“可以上溯 至龙山文化、良渚文化玉石器上神秘的图腾纹饰”。[11] (p241)

赣傩所表现的民俗文化内容, 现存傩舞傩戏节目二百 多个, 不仅题材广泛, 而且功能多样。就其题材而言, 或 取材于神话故事, 或取材于民间传说, 或取材于历史典故, 或取材于释道宗教, 或直接表达乡人现实愿望; 按其功能 来说, 既有表现驱邪逐鬼力量的, 亦有表现迎神祈福理想 的, 还有表现乡人现实生活情趣的, 等等。

例如, 取材于上古神话的《开天辟地》, 开山神盘古 是傩坛大神, 他双目圆睁, 手舞钸斧, 四处搜寻, 左推右 挡, 上䢃下砍, 相貌可怖, 为傩神先导开路, 驱赶鬼疫, 除妖净坛, 表现了他那开创乾坤、勇往直前、无坚不摧的 英雄气概; 《后羿射日》中塑造了后羿这个神勇非凡、造 福于民的英雄形象, 他张弓搭箭, 下杀猛兽, 上射太阳, 拯万民于水火之中, 表达了古代劳动人民征服自然、改造 自然的美好愿望。此外, 如《傩公傩婆》伏羲女娲创生的 神话、《跳白》白泽神兽言鬼神的神话、《跳判》钟道不 同来历的神话, 以及 《猴子悬梁》《捉猿精》 《孙悟空》 反映猿猴图腾之类的赣傩神话, 均折射出赣鄱悠久的历史 文化影迹。

取材于民间传说的《孟姜女送寒衣》，表演孟姜女新 婚燕尔, 丈夫范喜良就被抓去修筑长城, 秋去冬来, 她千 里为夫送寒衣, 当来到长城边得知夫已饥寒劳累而死。于 是乎, 孟姜女哭天抢地, 感动上天, 致使长城倒塌八百里, 终于找到丈夫的骸骨, 以新衣殓夫安葬后于绝望中投海而 尽; 傩剧气势恢宏, 笼罩着一种悲壮的气氛。此类赣傩戏 剧还有: 行侠仗义的《鲍三娘和花关索》、财神斗法的《刘 海戏金蟾》、订鬼驱邪的《钟旭扫台》以及传说中的八仙 故事如《跳八仙》 《跳十仙》 《八仙祝寿》 《下凡出世》
等, 无情地鞭挞了为非作歹的丑恶势力, 热情地歌颂了惩 恶扬善的正义力量。

取材于历史故事的《舞花》, 是一组大型舞剧, 由《放 叉打旗》《元帅操兵》《土地巡游》《送药酒》《饮毒酒》 等片段构成, 各段之间即可首尾相连, 又能独立成篇, 主 要表演秦二世胡亥谋害兄长、篡夺皇位的故事。该剧描写 秦始皇死后, 太子扶苏在上郡监蒙恬大军, 其弟胡亥差丞 相李斯假借慰劳大军之名, 带着毒酒谋害兄长扶苏, 以达 到登上皇帝宝座的目的, 场面壮观, 气势磅礴, 再现了封 建统治者权利斗争的残酷。《关公磨刀》则表演关公磨刀 降恶龙、解除民间疾苦的故事。民浐有“大旱不过五月十 三”之说, 倘若这天龙王没有布雨而误了关公磨刀的大事, 关老爷就要爆发雷霆, 大闹龙王殿, 直到六月六日龙王布 下大雨才肯罢休。为了救万民于灾难之中, 每年五月十三 日这天, 关公都要亲临南天门磨刀示威, 并令龙王降下雨 霖。傩戏把关公表演得栩栩如生: 红脸关公挥舞着“青龙 偃月刀”, 然后将其架在磨刀石上, 来往“霍霍”地磨它几 个回合。每当此时, 观众情绪高涨, 喊声震天, 使人仿佛 回到那战火纷飞的三国古战场, 瞧见了当年那气吞山河、 所向无敌的关羽英姿。表演历史题材的, 还有诸如寇准、 范仲淹、包拯、秦叔宝、尉迟恭、华佗、孙思邈等儒家人 物和英雄神将的故事。

赣傩还取材于道释宗教, 使之具有道释文化因子, 主 要表现在以下几方面: 其一, 以其神灵体系, 壮大傩坛威 力。如傩神中有紫微大帝、太白金星、真武大帝、八仙、 刘海、张天师、关公等道教神仙和护法神将, 还有如来佛、 弥勒佛、观音、金刚、阎罗、十八罗汉、四大天王等佛教 菩萨和护法神。其二, 以其礼仪制度, 丰富赣傩驱鬼逐疫 仪式。其三, 以其思想内容, 拓展赣傩娱乐功能。如赣傩 中既有道教神驱邪斩妖、五行相生相克内容, 又有释家普 求终生、因果报应观念, 还有儒家读书入仕、“神道设教” 思想, 等等。赣傩可谓兼收并蓄, 其文化内容丰富多彩, 呈现出多元化特色。

赣傩有些内容还反映了崇尚生命、繁衍子孙的习俗。 例如, 万载跳傩舞时, 观者携儿带女进其凉伞下, 以求傩 神保佑; 宁都一跳“禳神”舞, 乡民这天就将满月小孩同重 阳高寿老人安排于一起, 希望孩子寿高重九; 南丰不仅有 生子“喜事傩”，还有还愿、拜契、打关等为小孩辟邪免灾 的傩俗; 石邮村“搜傩”时, 男孩可登上神坛与傩神太子一 道观看。

赣倠求子祈丰的仪式, 后又衍生出祈福、纳吉、求财、 兴旺等丰富内容。如神词赞诗: “一愿家家庆吉, 二愿夫 妇均安, 三愿田禾大熟, 四愿猪牛兴旺, 五愿五谷丰登, 六愿大众千秋。”求嗣者, 早生贵子。”读书者, 聪明智 慧, 求功名早登金榜; 农耕者, 一籽落泥, 万籽收成; 做 技艺者, 上家相谐, 下家相迎; 做生意者, 一钱为本, 万 钱为利。”此外, 还有祈求吉祥平安 (如《财神》《鬼星》 《和令》 《鸡嘴》《猪嘴》) 和表达农耕情结（如《獭捉 鲤鱼精》) 等傩戏内容。这类节目已从“神化”转向“人化” 了, 洋溢着人世间浓郁的生活乐趣。像《十八罗汉》这样 的节目, 是傩戏艺人的自娱自乐, 已从“娱神”中解脱出来 了, 趋近于“人化”的杂要表演。 
从上述所反映的赣倠历史和文化内容来看, 其历史悠 久而厚重, 内容丰富而多彩, 风格粗犷而古朴, 既继承了 历经岁月所沉淀的优良传统艺术, 又发扬了不拘成规适时 变革的创新精神。也就是说, 赣傩是在继承中有所发展, 又在发展中有所继承的, 它在保持“中国古代舞蹈活化石” 的基础上, 反映了当今社会人们锐意进取、追求幸福生活 的时代风貌。

\section{4. 赣倠民俗文化中的方言俗语}

上已述之，先秦时期赣省曾长期活跃着三苗、百越及 吴楚等民族, 其尚鬼、崇巫、喜卜、好祀之风不仅深深地 影响了赣省的民间习俗，而且还孕育着赣傩文化。尽管历 经数千年, 但赣倠如今仍然遍布于城镇与乡村, 构成了赣 鄱民俗文化中一道郬丽的风景。赣傩民俗文化不但内容丰 富, 而更为独特的是其具有鲜明而浓郁的地方特色, 而这 独具的特色又与其傩戏大量运用方言俗语密切相关。

赣鄱傩戏民俗文化所运用的方言俗语主要体现在以 下几个方面: 一是产生于赣傩祭祀仪式中的方言俗语, 二 是产生于赣倠表演艺术中的方言俗语, 三是产生于赣傩民 俗心理中的方言俗语。

\section{1. 产生于赣倠祭祀仪式中的方言俗语}

赣鄱倠事活动主要集中在春节期间, 但各个地方傩事 活动的时间、内容及称名等都存有一些差异。在赣鄱倠事 活动中, 傩祭仪式是其十分重要的一个组成部分, 相应的 也产生了不少特殊的方言俗语。

从赣傩活动程式看, 老傩班是由“起傩一演焳一驱倠 一圆傩”等基本仪式构成。

“起傩”，这是一个大傩下殿仪式，除了“开洞”“出 洞”“出案”“开箱”等俗称之外，老傩班还谓之“下座”, 新倠 班又称之“放圣相”。也就是, 将装面具的箱笼从傩神殿阁 楼上放下来, 一一取出面具, 用茶叶水洗抹干净, 换过面 具耳索口绳, 或搬上神坛, 或悬挂坛前, 或置于供桌上, 然后奉上供品, 点燃香烛, 燃放鞭炮, 众弟子作揖参拜。 一般说来, 大傩班正月初一下殿, 把装圣相的木柜打开, 乡人俗称“开殿门”; 然后由傩班头人“大伯”（一些地方俗 称“正印”“头人”“首士”“老座”或“倠长”）率领弟子于傩神 庙焚香礼佛, 燃放鞭炮, 踭拜祈福。

在大傩下殿程式中，还有“下答”（即占卜）这样的仪 式，俗称“判答”或“跌等仂”。“下答”，就是仪式主持人把 一竹制竹节形或木制桃形一剖为二, 并将其掷于地, 若掷 成“圣答”（一片向下，一片向上，称之“一阴一阳”），表 示傩神同意; 若掷成阴等 (两片向下) 或阳答 (两片向上), 则表示傩神不同意，必须继续掷答，直至掷成。

紧接着“出殿”, 俗云“出神”。此时, 众弟子把圣相取 下, 将其装进箱笼后, 有的挑箱笼, 有的扛把子, 有的打 家什, 热热闹闹地奏乐出殿, 然后一齐回身行礼, 辞别倠 庙, 守殿人则以鞭炮相送。傩班弟子每天早晨到傩神庙举 行简单的请神、祭神仪式，乡民称之为“上马”。

“演傩”, 乡民将之俗称为“跳傩”“跳鬼当”“跳鬼”等, 即 表演傩舞节目内容, 如《开山》《雷公》 《纸钱》等, 既
娱神又娱人。“演傩”的主要形式有: 或祠堂跳傩, 如上甘 村、石邮村; 或福主殿跳倠, 如杂姓村庄; 或各家跳傩, 如石邮班、周家堡班、上古班; 或场地跳倠, 有的大傩班 找块开阔地表演, 乡民谓之“畴场”。

每当演完之后, 回傩神殿则要举行回神仪式, 乡民谓 之“下马”。此时, 弟子把圣相从箱笼中取出, 仍重放原处 或置于桌上供奉。

“驱倠”, 这是大傩仪式中的第三步, 谓之“扫堂”“行靖” 等俗名, 是整个傩祭仪式中的实质性部分, 多在正月十六 日举行。“驱倠”仪式主要由弟子扮作捉鬼神祇, 配以“咚 咚”锣鼓声, 挨家挨户搜鬼驱疫, 把鬼疫捉住, 解押出门, 将其“解迁”到水口外让水流走。大傩班仅搜厅堂, 不搜房 间, 俗称“太平傩”。“驱倠”有“请坛”“催神”“插路香”“请 神”“跳倠”“搜除”“解迁”““拜师”“辞神”“送神”“班师”等主要 仪式, 有的地方还包括“合傩”“参神”“只马马“添粮”“请神起 马”“倠庙搜傩”“上马参神”“参牌坊”等内容。一般说来, 老 傩班及部分新傩班是沿袭古傩沿门驱疫的, 其俗名各有差 异, 如上甘、上古、池渡、朱坊等地称之 “解倠”, 石邮、 庙前、大圆、祝家岭等地谓之“搜倠”, 新田名之“搜除”, 而新倠班大多言之“圆傩”。

“圆倠”，乡民谓之“收倠”“封箱”“封洞”“收案”等，这 是大傩仪式的尾声。驱倠结束之后, 傩班弟子来到村旁河 滩, 将大傩面具依序摆放沙滩上, 接着参拜圣像, 酬谢各 路神灵, 送倠神归位, 乡民称之为“参圣像”; “参圣像”完 毕后便是“判珓”, 这是对整个傩事活动的一个总结。当然, “圆傩”与“驱倠”的仪式界限甚为模糊, 如朾江西岸南丰石 邮村“圆傩”仪式就是“驱傩”后的“参圣像”“回殿”“谢 师”“安座”“上殿”等活动, 而朾江东岸则包含象征性驱疫仪 式，跳完傩后仅有“上殿”“做会”两项仪式。所谓“上殿”, 俗称“上座”或“安座”, 即请大傩面具神祇归位; 所谓“做 会”, 就是傩班弟子与参加傩班活动的人员, 包括管理族 傩的头人、入股的村民等聚会加餐, 总结当年的跳倠情况, 结算经费收入与开支, 安排下年傩事活动。

\section{2. 产生于赣倠表演艺术中的方言俗语}

赣倠艺术丰富多彩, 形制各异, 独具地域特色, 如倠 舞、傩戏、傩面具等就构成了赣傩艺术中的景观, 而且还 产生了大量的方言俗语。此处择其精要, 以管窥豹。

傩舞是赣傩艺术中的主要表演形式, 一方面吸收了儒 道释文化因子, 另一方面又融入了地域民俗元素, 因而形 成了独具特色的民间舞蹈艺术。

赣倠舞蹈表演形式灵活多样，不拘一格，除大年佳节 喜庆外, 平时无论婚娶添丁, 生日做寿, 还是迎神驱鬼, 祭祖丧孝, 都要请倠班跳舞。例如, 每逢喜事时, 农家都 会请傩班来家“跳几角傩”: 结婚人家跳的舞乡民俗称“参 新人”, 生子跳的谓之“参伢子”, 生日做寿跳的言之“参寿”, 乔迁新居跳的称之 “参花居”，等等。所有这些，乡民皆称 之“喜事舞”。此外, 还有一种“还愿舞”, 指的是某人许愿 后, 便在当年或次年“还愿”, 诸如祭祀丧孝还愿, 天灾人 祸还愿, 甚至红喜事也还愿。在跳“还愿舞”的过程中, 有 所谓的“启师”, 他用竹策扎一船形骨架, 以供牵主家神拿 烧香鸣爆, 念“启师咒”; 然后, 便一边糊纸“船”, 一边唱 
“造船咒”; 紧接着，将“船”抬至每个屋角，把“摄毒”装进 “船”里, 乡民俗言“收瘟”; 最后, 傩舞队将“船”抬至河边, 边唱边把鸭血淋于“船”身烧掉，乡民曰之“焚船”。[12] （p54）赣傩舞蹈艺术风格古朴、简练、粗犷、形象, 手 势舞姿或优美动人, 富于生活气息; 或粗犷刚劲, 具有节 奏韵律，乡民称这为“拗诀”。

傩戏是在傩舞的基础上发展而成的戏曲样式, 有“正 戏”“外戏”“插戏”“小戏”“串戏”之称。赣鄱四大傩戏分别 是: 柔源傩戏、南丰傩戏、萍乡傩戏、万载傩戏。另外, 还有受“跳倠”影响很深的广昌“孟戏”，也颇有特色。在跒 源，有一种独特的傩戏，乡民称之“地戏”; “地戏”又分为 所谓的“地戏”“马戏”“台阁”“高跷”之类。之所以称为“地 戏”, 因为其是地上行走而表演的; “马戏”, 为乘马游行 而表演的; “台阁”，则由四至八人抬一桌子，或站立、或 坐下、或倒立、或悬空而表演的; 而“高跷”, 即在脚上绑 着木棍, 边行走边舞着而表演的。[12]（p170）傩戏一般 在祀社、祀灶、还愿、神出巡、赛庙会等场合演出。[8] （p175）例如，广昌“孟戏”每年元宵前三天，择个吉日“起 戏”(即开始演出), 起戏那天上午要抬菩萨游村, 名曰“出 帅”; 如晚上演出, 之前则要在河边木桥的“王墩”上点燃 蜡烛, 将燃着的蜡烛一直插到祠堂屋檐下为止, 也即乡民 所说的“插路烛”。紧接着要“请神”，由所谓的“管首”(宗族 首领)捧神本念唱, 拜请各山大刹诸神和孟戏已故艺人看 戏。如第一夜演出, 要作“打钱”仪式, 保佑合坊大吉昌; 整个演出结束后, 还要“辞神”。[13]（p65-66）

行傩仪、跳傩舞、演傩戏离不开傩神面具。如果没有 傩神面具, 那么傩仪、傩舞、傩戏表演艺术就大为逊色, 所以傩神面具也就成了赣傩艺术中的一个不可或缺的组 成部分。关于傩神面具称名，乡民有不少俗称，如“假 面”“菩萨”“神像”“圣像”“圣相”“鬼面”“盔头”“脸仂”“面壳 子”等。傩神面具主要由面孔、盔帽、耳翼三部分构成, 制作傩神面具的艺人俗称“处士”。傩神面具制作完成之 后, 则要举行“开光”仪式, 三五年之后重漆一次, 乡民称 之“着衣裳”。“开光”仪式有的地方也称“开箱”仪式, 一般 为半夜时由“土师”率领男丁前往村中最高山顶作法, 其有 所谓的“起坛”“暗坛”“偷水”“接喜”“请圣”“安心词”“点 光”“照光”“祝神”“送神”“安坐”“谢师”等程式。实际上, “请 圣”前还有所谓的“练将”仪式，程式谓之“起北斗”“踩北 斗”“洗脸”。从傩神面具艺术看, 其风格粗犷浑厚, 线条 简洁流畅，集宗教、审美、民俗于一体，反映了人性的一 种本质力量。

\section{3. 产生于赣傩民俗心理中的方言俗语}

神傩是一种特殊的综合性文化现象, 它涉及物质、社 会、精神等方面的内容, 这些内容相互影响, 相互渗透, 共同构成了一种错综复杂的民俗文化心理关系。

赣傩民俗是赣鄱地区神傩与民俗相互结合的产物, 其 类型多样, 形态各异, 内容丰富, 已经成为赣鄱民俗文化 中一个重要的组成部分。在其丰富多彩的神傩民俗文化 中, 也产生了不少的方言语汇, 这些方言语汇或为物质方 面的, 或为社会方面的, 或为精神方面的; 无论那个方面, 都表现出那种消灾辟邪、祈福纳吉的民俗文化心理内容。
赣鄱地区, 表现衣、食、住等生活生产方面的傩俗, 不仅历史悠久, 传播的范围广, 而且影响也大。例如, 先秦两汉传承下来的，不仅有乡民所说的“抢头帕”“许愿 还袍”“佩饰灵物”等服饰傩俗, 还有“供饭祈福”“添粮回 神”“做傩会”等饮食傩俗。其中有些傩俗事象还比较复 杂, 如“供饭祈福”是跳傩间乡民为傩神与弟子供饭或点 心的一种活动, 供饭或点心大多为糯糍、糯饭、酒菜、 米果之类, 如仅有酒、米果而无面食, 乡民称之“酒点心”; 他们认为这是一种荣耀, 既可向神表示敬意, 又能向神 祈求福运。而“添粮回神”的礼节较多, 乡民称弟子吃饭 为“添粮”, 其间的仪礼有: 一是答谢, 众弟子向主人齐 说“多谢！”主人回礼“托老爷的福”，然后喝酒前众弟子 以右手中指沾酒或茶水先向左耳旁用大拇指弹一下，再 向右耳旁弹一下，乡民谓之“谢师”; 二是回神，众弟子 吃饭后与主人全家酬谢祖宗; 三是念灶单, 也即圆傩后, 向傩神汇报跳傩间供饭、点心乡民姓名, 为其祈福。又 如, 每年圆傩后, 各傩神会要集中弟子及相佐人聚餐, 说是要“沾点傩神老爷的福气”, 乡民俗称“做傩会”或“做 会”, 籍以庆贺傩事圆满结束; 有的地方凡捐助圣相、把 子、角笼、庙基, 乡民聚餐各家一人, 言之曰“办圣像饭”。 此外，古代传下来的还有所谓的“贴门神”“挂吞兽”“立狮 座”“安兽头”等宅院傩俗, 这些傩俗至今在不少地区还十 分流行。乡民常把“贴门神”称之为“桃人”“桃梗”或“桃 符”“桃神”; 之所以如此称谓, 是因为秦汉时先人常于户 外立一桃木所刻的守门神驱鬼疫, 或在桃木门上画神茶、 郁垒神像, 以之辟邪。“挂吞兽”, 乡民谓之“吞口”“吞头” 或“啸山”, 这种吞魔食怪的神兽是由秦汉时门上画的虎 食鬼演变而成的。

赣鄱地区, 表现在人生仪礼诸如诞生、成丁、婚姻等 方面的倠俗, 也是颇有历史年载和影响力的, 其内容较多 地反映乡民祈福禳灾的思想意识和美好期待的社会心理。 在这类社会生活的傩俗中，乡民有求嗣跳“二郎发弓”舞的 习俗。所谓“二郎”, 即送子张仙之名号; 他发弓射弹, “弹” 实为“诞”之谐音, 亦即㚣儿“诞生”义, 据说这是上古祭祀 高禖授弓求子仪式演绎而成的。有的人生子后, 还要做一 张小竹弓送给菩萨，乡民名之曰“还箭”。有些地方，乡民 为了给小孩避疫消灾，不仅为孩子取“傩”名，还有“拜契” 的习俗。所谓“拜契”, 就是跳傩期间父母带着肉、鸡、鱼、 面条、糯糍、香烛等乡民所说的“禄礼”，领着孩子上傩神 殿，拜傩神为“契爷”（即“干爹”），求其保佑孩子身体健 康无病灾。当然, 只有收了“禄礼”之后, 傩班正、副印才 为他卜䇤, 请求傩神应允。

此外, 赣鄱地区还有与巫术意识有关的诸如傩神信 仰、傩中占卜、傩事禁忌、符等咒语以及带有宗教色彩等 方面的方言俗语。例如, 傩事禁忌就有语言禁忌、饮食禁 忌、人身禁忌等方面的独特用语。

\section{5. 结语}

一言而概之, 赣傩民俗文化不仅内容丰富, 而且有 着十分悠久的发展史。赣傩所催生的系列傩事活动, 也 产生了大量反映神傩事象、具有地域特色的方言俗语。 尤其上古时期, 一些如三苗、百越及吴楚等民族敬鬼重 
祀之风对赣鄱地区产生了非常强烈的影响，成了赣傩衍 生发展的深厚土壤。早期的赣傩不但融汇了多种文化因 子成分，实质上它还是一种集宗教、民俗、艺术于一体 的人神对话, 其内容具有鲜明的神灵主宰倾向以及宗教 色彩意识。诚然, 随着社会发展的不断进步, 乡民思想 观念的不断更新, 赣傩民俗文化内容也焕然一新, 其中 渗透了不少现代音乐舞蹈等文化元素, 使之逐渐朝着大 众化、生活化、娱乐化方向发展, 其表演永恒的主题始 终是如意吉祥, 幸福安康, 欢乐共享。不仅如此, 乡民 甚至还将赣倠表演与当地经济产业结合起来, 如南丰、 柔源就以傩俗文化为其旅游业服务, 通过傩舞表演向外 展示其独特的地域文化。

进入新时期以来，作为宝贵的历史文化遗产而加以 挖掘和保护的赣傩民俗文化, 在推进地域文化建设中, 正以国家意志和价值观念书写着它的崭新内容, [14]不仅 焕发了新的生命活力, 还在海内外产生了很大的影响。 例如, 赣傩十多次参加了国内（包括香港、台湾地区） 民间艺术汇演, 多次赴日本等地或参加国际学术会议展 览演出, 引起了很大的轰动, 被誉为中国舞蹈的“活化 石”，甚至还有学者惊叹“中国戏剧史或许将因此而改写” (著名戏剧作家曹禺语), 其傩舞专题片在国内外数十 家电视台持续热播, 而且2005年来自美、韩、日、俄、 法等20多个国家400多名中外专家学者, 齐聚赣省南丰参 加“中国江西国际倠文化艺术周”田野采风, 使其声名远 播国内外。不仅如此, 上世纪末本世纪初, 国家文化部 和江西省文化厅还将南丰、歌源、乐安、崇仁、永丰、 永新、萍乡、万载、德安等地倠舞列为国家和省级非物 质文化遗产而加以保护。对于赣傩艺术价值, 中国傩戏 学研究会会长、著名戏曲理论家曲六乙曾经评价说: “我 认为, 它比周边省份的傩文化更古老稚拙, 更粗犷豪放, 更具原生形态特征, 因而在人类学、宗教学、民俗学、 艺术学、戏剧学等领域, 具有巨大的学术价值和资料价 值。”[15]（p2）

赣傩文化是赣鄱传统文化的重要组成部分, 也是源远 流长的中国傩文化的一个重要组成部分。因此, 在新时代 物质文明和精神文明建设的历史条件下, 不仅要充分地开 发利用好这一非物质文化遗产的宝贵资源, 还要采取强而 有力的措施保护发展好这一宝贵资源, 使之放射出新的更 加璀璨的光芒。

\section{致谢}

基金项目: 国家社科基金重大项目“600年来赣语与官 话互动的历史追踪、现状调查与数据库建设” (编号 18ZDA297）; 江西省社科联规划重点项目“赣鄱方言与民 俗文化研究”（编号13YY01）。

\section{参考文献}

[1] 肖九根, 黎清.赣鄱陶瓷民俗事象及其方言俗语之管见 [J]. 江西师范大学学报(哲社科版) 2019(06).

[2] 郝宁静.刍议赣傩 [J].戏剧之家2016(20).

[3] 张劲松.七千年前的“禾魂祭”及其与傩源之关系[J].民间文 学论坛1994（04）.

[4] 刘洋, 邱洁, 李蕾.从社会传播视域下论江西倠文化在生活 中的转变 $[\mathrm{J}]$. 戏剧之家2018(14).

[5] 江西省文物考古研究所.新干商代大墓[M].北京：文物出版 社, 1997.

[6] 周广明.吴城商代宗教祭祀场所探究[J].南方文物1994(04).

[7] 江西省文物考古研究所. 江西德安米粮铺遗址发掘简报 [J]. 南方文物1993（02）.

[8] 邰乐.从傩乐的变迁看文化遗产的传承与发展 [J].音乐创作 2017(06).

[9] 彭适凡.赣鄱地区音乐文化概述[J].南方文物, 2002(02).

[10] [德]罗泰. 论新干大洋洲出土的青铜乐器 [J]. 江西文物, 1991(03).

[11] 丁武军.江西体文化的旅游开发研究 $[\mathrm{A}]$, 文化与旅游 $[\mathrm{M}]$. 北京: 中国文联出版社, 2004.

[12] 蔡社宝, 周关.赣傩[M].南昌:江西教育出版社, 2007.

[13] 毛礼镁.江西傩及目连戏[M].北京: 中国戏剧出版社, 2004.

[14] 李晓方.明清南赣方志王阳明历史书写的时空形态及其变 迁[J].江西师范大学学报（哲社科版）2019(02).

[15] 曾志巩.江西南丰傩文化[M].南昌: 江西人民出版社, 2014 . 